\title{
Pesticides and Breast Cancer
}

\author{
Roberto Ferro, Arvin Parvathaneni*, \\ Sachin Patel, Pramil Cheriyath \\ Pinnacle Health, Harrisburg, USA \\ Email: *doctorarvin@gmail.com
}

Received June 7, 2012; revised July 15, 2012; accepted July 24, 2012

\begin{abstract}
Along with other etiological factors like genetics, family history, age, etc. there is growing scientific evidence that exposure to chemicals, including pesticides is associated with increased incidence of breast cancer among women. Various animal studies have demonstrated the carcinogenic effect of pesticides byacting as Xenoestrogen, interacting and disrupting estrogen receptors or by damaging breast tissue DNA inducing malignancy/catalyzing existing DNA mutation in susceptible individuals. Pesticide's role as a contributing etiological factor in growing incidence of breast cancer is of particular concern as pesticides is one of the chemicals to which humans get exposed every day in significant concentration. In this review we describe various kinds of pesticides and their respective associations to breast cancer.
\end{abstract}

Keywords: Breast Cancer; Pesticides

\section{Background}

Breast cancer is the second most common cancer occurring among American women, after skin cancer [1], with incidence rate of 124.3 per 100,000 women per year. It is also the second leading cause of cancer related mortality in women with high mortality rate of 23.0 per 100,000 women, followed by lung cancer. According toAmerican Cancer Society (ACS), in the year 2012, 226,870 new cases of invasive breast cancer will be diagnosed and 39,510 women will die from breast cancer. Incidence rate has steadily increased from 1 in 20 women in 1961 up to 1 in 8 women in 2010 [1].

Along with other etiological factors like genetics, family history, age, etc. there is growing scientific evidence that exposure to chemicals, including pesticides is associated with increased incidence of breast cancer among women. Various animal studies have demonstrated the carcinogenic effect of pesticides byacting as Xenoestrogen, interacting and disrupting estrogen receptors or by damaging breast tissue DNA inducing malignancy/catalyzing existing DNA mutation in susceptible individuals.

Pesticide's role as a contributing etiological factor in growing incidence of breast cancer is of particular concern as pesticides is one of the chemicals to which humans get exposed every day in significant concentration. Most of the exposure to harmful carcinogenic agents is through food, water, products used to control pests likeherbicides (weeds), fungicides (fungi), insecticides (in-

${ }^{*}$ Corresponding author. sects) and Rodenticide (rodents), cosmetics, plastics, pharmaceuticals etc. Environmental Protection Agency (E- PA) is responsible for regulating pesticides under the Federal Insecticide, Fungicide, and Rodenticide Act (FIFRA) and the Food Quality Protection Act (FQPA). EPA provides federal control of pesticide distribution, sale, and use. However, their regulatory laws are based on risk benefit ratio, giving more weight to economic benefits of pest control against health and environmental hazards posed by them. In this review we describe various kinds of pesticides and their respective associations to breast cancer.

\section{Definition of Pesticide}

As per Food and Agriculture Organization (FAO); Pesticide is any substance or mixture of substances intended for preventing, destroying or controlling any pest, including vectors of human or animal disease, unwanted species of plants or animals causing harm during or otherwise interfering with the production, processing, storage, transport or marketing of food, agricultural commodities, wood and wood products or animal feedstuffs, or substances which may be administered to animals for the control of insects, arachnids or other pests in or on their bodies, also included are substances intended for use as a plant growth regulator, defoliant, desiccant or agent for thinning fruit or preventing the premature fall of fruit and substances applied to crops either before or after harvest to protect the commodity from deterioration during storage and transport. 


\subsection{Groups of pesticides based on the target organism}

\begin{tabular}{cc}
\hline Type of pesticide & Target pest group \\
\hline Algaecides or algaecides & Algae \\
Avicides & Birds \\
Bactericides & Bacteria \\
Fungicides & Fungi \\
Insecticides & Insects \\
Miticides or acaricides & Mites \\
Molluscicides & Snails \\
Nematicides & Nematodes \\
Rodenticide & Rodents \\
Herbicides & Unwanted plants \\
\hline
\end{tabular}

\subsection{Groups of pesticides based on chemical composition}

\begin{tabular}{ccc}
\hline Insecticides & Herbicides & $\begin{array}{c}\text { Persistent organic } \\
\text { pollutant }\end{array}$ \\
\hline $\begin{array}{c}\text { Dieldrin/aldrin: } \\
\text { organochlorine } \\
\text { Heptachlor: } \\
\text { organochlorine } \\
\text { Ddt/dde: }\end{array}$ & Atrazine: triazine & PCBs \\
organochlorine & & Dioxin \\
Malathion: & & DP: auxin \\
organophosphates & & \\
\hline
\end{tabular}

\section{Pesticides Associated with Breast Cancer}

\subsection{Triazine}

Triazine group of chemicals are most widely used herbicidesin the world. This group consists of atrazine, simazine, propazine and cyanazine. Among all triazines, Atrazine is of particular concern because it is one of the most widely used herbicides with 76 million pounds of it applied each year as it is economical and effective. Epidemiological studies have shown that it is associated with Breast cancer in women and other ecological disruptions. Continuous use of atrazine as the primary herbicide for years has resulted into contamination of ground water and soil with it.

Elevated levels of atrazine have been demonstrated in water and soil each spring and summer, particularly in agricultural areas like Midwest where it is primarily used to control weeds in cornfields. Increasing Atrazine use is concerning as United States and other countries are mulling on corn production for ethanol, resulting in con- current rise in use of Atrazine herbicides and its associated toxicity.

Atrazine is a known endocrine disruptor. It interferes with Pituitary-Ovarian axis decreasing Prolactin and luteinizing hormone levels, the changes which contribute to increase in mammary gland tumor [2].There is documented evidence of Atrazine causing dramatic damage to reproductive structures in frogs, fish and other wildlife [3], however correlational human studies are lacking. Atrazine also induces increased aromatase enzyme activity resulting in increased levels of estrogen which is directly linked with Breast cancer [4]. Studies by Ueda et al. showed significant acceleration in tumor cell proliferation when experimental rats with existing breast cancer were exposed to Atrazine compounds [5]. Studies by Raynor et al. concluded that Inutero exposure of Atrazine compounds results in delayed development of mammary glands, a known risk factor for breast neoplasm [6].

Current standards for drinking water restricts atrazine to 3 parts per billion in United States, but from studies, it has been concluded that Atrazine is harmful even at levels of 0.1 parts per billion, which is 30 times lower than the current drinking water standard in the United States. Atrazine was banned in European Union in 2005 because of the persistent ground water contamination caused by it and studies indicating its carcinogenic potential for mammary gland, prostate and also its correlation with ecological disruption. But it is still widely used in USA as Environmental Protection Agency (EPA) is reluctant to ban Atrazine as it considers Atrazine's risk benefit ratio in favor of its use as an herbicide.

\subsection{Di-Chloro Di-Phenyl Trichloro Ethane (DDT/DDE)}

DDT was one of the most widely used insecticide in the world, successful in eradication of malaria from USA and other countries, though at an expense of devastating environmental problems and human health hazards. Multiple case control studies have shown a correlation between blood DDT/DDE levels and development of Breast malignancy. Cohn. BA et al. carried out a prospective, nested case control study to analyze the relation between age of exposure to DDT and subsequent breast cancer occurrence later in their life. In that study 129 cases developed breast cancer by the age of 50 years as opposed to 129 controls $(p=0.02)$. It concluded that women who are exposed to DDT and its metabolitesin early half of their adolescence (first 14 years of women's life) have 5 fold more risk of having breast cancer later in their life than those women who had same amount of exposure after first 14 years of their life [7]. Retrospective case control studies by Charlier et al. indicate that certain pollutants like DDT and its metabolites are present insignificantly higher concentration in women with breast 
cancer when compared to the control group [8]. A case control study to analyze the relationship between DDT levels, lactation history and breast cancer occurrence, by Romieu et al. deduced evidence of dose response relationship of breast cancer with DDE in serum (highest compared with lowest quintile $\mathrm{OR}=3.81 ; 95 \% \mathrm{CI}, 1.14$ 12.8) [9]. In a hospital based case control study by Demers et al. to investigate the relation between blood DDE levels with staging and grading of tumor, a positive correlation was found between increased doses of DDE and its metabolites with aggressive tumors with lymph node involvement indicating that DDT/DDE might aggravate malignancy of mammary glands, if not initiate it [10].

\subsection{Dieldrin and Aldrin}

Dieldrin and Aldrin were commonly used insecticides in corn fields till late 1980's when they were banned in United States in 1987 due to concerns posed to environment and human health. Dieldrin mainly acts as a Xenoestrogen and also disrupts Androgenic pathways. Addition of Dieldrin into MCF-7 (Michigan Cancer Foundation-7) human breast cancer cell in vitro lead to cells accelerated growth and proliferation. (Andersen, 2002; Soto, 1994) [11]. Exposing experimental rats, prenatally and neonatally with environmentally relevant doses of Dieldrin resulted in increased incidence of breast cancer among them, likely mechanism of it may be Dieldrin mediated changes in cellular expression of BNDF and cell signal receptors Heroin breast tissue [12]. In 1998 a cohort study conducted by Copenhagen Center for prospective studies concluded that Dieldrin is associated with increased incidence, incidence of aggressive tumor and higher mortality in breast cancer. The result from the study showed a dose-related increase in risk of breast cancer (adjusted odds ratio of 2.05). This study also concluded that tumor grading and staging is directly proportional to blood Dieldrin levels [13].

\subsection{Heptachlor (HE)}

Heptachlor is a well-known carcinogenic insecticide which was widely used before 1980 . Its commercial use was banned in 1988 except for controlling the fire ants in underground structures like buried pad-mounted electric power transformers, and in underground cable television and telephone cable boxes. Heptachlor has long half-life in environment and its residues can be found 14 years after its intended use.

Heptachlor Epoxide, metabolite of heptachlor gets accumulated in adipose tissues including mammary gland. HE (Heptachlor Epoxide) alters the hepatocytes inducing hepatocellular carcinoma. In a study by Classidy et al. using sparing extraction coupled with gas chromatography to determine the levels of HE, OC, and DDE in adi- pose tissue within breast biopsies in a series of 34 women evaluated for breast abnormality, only HE showed positive correlation with prevalence of breast cancer in the biopsies [14]. HE is a xenoestrogenic compound, combined with HE's ability to interact with NO induces an inverted-U increase in intracellular oxidants causing DNA damage and subsequent malignancy. Heptachlor also activated kinase signaling pathways resulting in accelerated proliferation of cancer cells (Cassidy, 2005) [15].

\subsection{Persistent Organic Pollutants}

Persistent organic pollutants (POP) are organic compounds which are resistant to environmental degradation and lipophilic (Brody, Moysich, et al. 2007), resulting in bio accumulation in human tissues causing endocrine, immune and reproductive system dysfunctions and malignancy including breast cancer. This group includes Poly Chlorinated Biphenyls, Chlorinated dioxins, furans, DDT etc.

\subsubsection{Polychlorinated Biphenyls (PCB)}

Though PCBs were banned in USA in 1977, as they are Persistent organic pollutant, they bio accumulate in human fat tissue over a period of time and also secreted in breast milk (Brody, Moysich, et al., 2007). A pilot study carried out by Falck Jr. F. et al. to measure and compare PCB levels in breast adipose tissue in women with malignant and benign neoplasm showed significant higher levels of PCBs in women with malignant neoplasm compared to benign counterpart [16]. Many studies concluded that genetic polymorphism plays a vital role in the association between PCBs and breast cancer risk. They also concluded that women with CYP1A1-m2 genetic variant, also referred to as the exon 7 variant (present in $10-15 \%$ of white women and higher percentage of African American women) (Li, Millikan, et al., 2005) are far more susceptible to PCB induced malignant changes in breast tissues [17]. A study done by Sijin Liue et al. concluded that PCBs enhance metastatic potential of breast cancer cells by activating Rho-associated Kinase (ROCK) [18]. Muscat et al. concluded that high PCB levels in breast tissue are directly related to breast cancer occurrence [19]. Hoyer et al. reported strong association between higher PCB values and mortality among women with Estrogen receptor positive tumors $(\mathrm{OR}=2.5 ; 95 \%$ CI, 1.1 - 5.7) [20].

\subsubsection{Polybrominated Diphenyl Ethers (PBDE)}

These compounds are structurally and functionally similar to PCBs and were widely used after PCBs were banned. A recent study done by Zhi-Hua Li et al. in china found out that PBDEs, especially PBDE-209 enhance proliferation of tumor cell lines in a dose depend- 
ent manner by altering cell growth cycle inducing $\mathrm{S}$ phase between G2 and M phase. PBDE-209 is also known to partially inhibit the cell apoptosis in breast cancer cells (MCF-7) and also suppresses Gö6976- and PD98059- induced apoptosis in all cell lines. Zhi-Hua Li et al. Concluded that PBDE induces proliferative effect on normal as well as cancer cell lines in breast and women's reproductive system, warranting further studies to confirm the role of BDEs in Breast cancer and other neoplasm of reproductive system among women [21].

\subsubsection{Other Pesticides}

Among other pesticides Chlordane, Malathion were associated with increased risk of breast cancer, specifically in young women or who had early onset of cancer. In a registry-based case-control study of breast cancer in farm labor union members in California, Mills PK, Yang R investigated new diagnosed 128 breast cancer patients and 640 cancer free controls which revealed this association [22]. Another large prospective cohort study undertaken by Lawrence et al. to evaluate the association between pesticides and occurrence of breast cancer among women whose husbands work in agricultural fields, revealed an increased incidence of breast cancer in women exposed to 2, 4, 5-triclorophenoxypropionic acid [23].

\subsection{Relation of Pesticides with Estrogen Receptor Status}

Most of the pesticides have xenoestrogenic properties, they interact with estrogen receptor acting as a weak estrogen, and hence their effect on Estrogen receptor positive breast cancer cells is worse when compared with estrogen receptor negative breast cancer. Epidemiological study conducted by Sophie St-Hilaire et al. to find out Estrogen receptor positive breast cancers and their association with environmental factors concluded that ER+ breast cancer develops aggressively when exposed to pesticides having xenoestrogenic effect than ER- breast cancer [24].

\section{Conclusions}

Despite efforts by environmental regulatory authorities to monitor the health effects of exposure to pesticides numerous people get exposed to these harmful chemicals each year. With the alarming rise of unsafe practices in agriculture the rate of this exposure is also escalating each year. There has been increasing evidence of association between pesticide use and occurrence of breast cancer across the world. The economic burden due to breast cancer in USA alone was 13.886 billion dollars in year 2006, which accounts to about 12.5 percent of total cancer care cost for all type of cancers in USA [25]. There is growing scientific evidence of association be- tween exposure to pesticide and increased occurrence of breast cancer. Many studies have identified the carcinogenic potential of pesticides like Atrazine, DDT, DDE, Dieldrin, Aldrin, Heptachlor, Polychlorinated biphenyls (PCB), Polybrominated diphenyl ethers (PBDE) and few others. They have been found to have positive correlation with incidence and aggressiveness of breast cancer. Interestingly, increase in incidence of breast cancer has paralleled the escalating consumption of pesticide in western countriespost-World War 2, and the trend is replicating in developing countries following increase in agriculture and concurrent increase in use of pesticides.

There are certain measures which if followed, significantly decrease the pesticide exposure and subsequent effect on breast tissue. Most common household measures includes taking precautionary measures while using pesticide sources like buying organic produce, buying produce from local farmers than from large store, Washing fruits and vegetables before use preferably with commercially available Commercial vegetable and fruit washes, identify the produce which has high pesticide content and avoid it, Using nontoxic methods for controlling insects like diatomaceous earth, which will kill a broad range of common indoor insects without posing any hazard to your family or pets, replacing all of house cleaning chemicals with nontoxic, environment friendly counterparts, etc.

Measures on larger scale includes enforcing tough regulations for pesticides suspected of having carcinogenic potential, development of effective methods to achieve optimum pest control with minimum use of pesticides, minimizing pollution of surrounding water and soil in communities, providing technical assistance to farmers for more effective and judicious use of pesticides and funding more research to develop pest resistant crops and environment friendly pesticides.

\section{REFERENCES}

[1] National Cancer Institute, "Surveillance Epidemiology and End Results." http://seer.cancer.gov/statfacts/html/breast.html

[2] R. L. Cooper, T. E. Stoker, L. Tyrey, J. Goldman and W. McElroy, "Atrazine Disrupts the Hypothalamic Control of Pituitary-Ovarian Function," Toxicology Science, Vol. 53, No. 2, 2000, pp. 297-307.

http://toxsci.oxfordjournals.org/content/53/2/297.full doi:10.1093/toxsci/53.2.297

[3] T. Hayes, K. Haston, M. Tsui, A. Honag, C. Haeffele and A. Vonk, "Atrazine-Induced Hermaphroditism at $0.1 \mathrm{ppb}$ in American Leopard Frogs (Ranapipiens): Laboratory and Field Evidence," Environmental Health Perspectives, Vol. 111, No. 4, 2003, pp. 568-575. doi:10.1289/ehp.5932

[4] W. Q. Fan, T. Yanase, H. Morinaga, T. Yanase, H. Morinaga, S. Gondo, T. Okabe, M. Nomura, T. Komatsu, K.-I. 
Morohashi, T. Hayes, R. Takayanagi and H. Nawata "Atrazine-Induced Aromatase Expression in SF-1 Dependent: Implications for Endocrine Disruption in Wildlife and Reproductive Cancers in Humans," Environmental Health Perspectives, Vol. 115, 2007, pp. 720-727. doi:10.1289/ehp.9758

[5] M. Ueda, T. Imai, T. Takizawa, H. Onodera, K. Mitsumori, T. Matsui and M. Hirose, "Possible Enhancing Effects of Atrazine on Growth of 7, 12-Dimethylbenz(a) Anthracene-Induced Mammary Tumors in Ovariectomized Sprague-Dawley Rats," Cancer Science, Vol. 96, No. 1, 2005 , pp. 19-25.

http://www.ncbi.nlm.nih.gov/pubmed/15649250 doi:10.1111/j.1349-7006.2005.00008.x

[6] J. L. Raynor, R. R. Enoch and S. E. Fenton, "Adverse Effects of Prenatal Exposure to Atrazine during a Critical Period of Mammary Gland Growth," Toxicological Sciences, Vol. 87, No. 1, 2005, pp. 255-266.

http://toxsci.oxfordjournals.org/content/87/1/255.full doi: $10.1093 /$ toxsci/kfi213

[7] B. A. Cohn, M. S. Wolff, P. M. Cirillo and R. I. Sholtz, "DDT and Breast Cancer in Young Women: New Data on the Significance of Age at Exposure," Environmental Health Perspectives, Vol. 115, No. 10, 2007, pp. 4061414.

http://www.ncbi.nlm.nih.gov/pmc/articles/PMC2022666/

[8] C. Charlier, A. Albert, P. Herman, E. Hamoir, U. Gaspard, M. Meurisse and G Plomteux, "Breast Cancer and Serum Organochlorine Residues," Occupational and Environmental Medicine," Vol. 60, No. 5, 2003, pp. 348-351. http://www.ncbi.nlm.nih.gov/pmc/articles/PMC1740527/

[9] I. Romieu, M. Hernandez, E. Lazcano-Ponce, J. P. Weber and E. Dewailly, "Breast Cancer, Lactation History, and Serum Organochlorines," American Journal of Epidemiology, Vol. 152, No. 4, 2000, pp. 363-370. http://aje.oxfordjournals.org/content/152/4/363 doi:10.1093/aje/152.4.363

[10] A. Demers, P. Ayotte, J. Brisson, S. Dodin, J. Robert and E. Dewailly, "Risk and Aggressiveness of Breast Cancer in Relation to Plasma Organochlorine Concentrations," Cancer Epidemiology Biomarkers \& Prevention, Vol. 9, No. 2, 2000, pp. 161-166. http://cebp.aacrjournals.org/content/9/2/161.full

[11] H. R. Andersen, A. M. Vinggaard, T. H. Rasmussen, et al., "Effects of Currently Used Pesticides in Assays for Estrogenicity, Androgenicity, and Aromatase Activity in Vitro," Toxicology Applied Pharmacology, Vol. 179, No. 1, 2002, pp. 1-12.

[12] H. L. Cameron and W. G. Foster, "Developmental and Lactational Exposure to Dieldrin Alters Mammary Tumorigenesis in Her2/Neu Transgenic Mice," PLoS One, Vol. 4, No. 1, 2009, p. e4303. doi:10.1371/journal.pone.0004303

[13] A. P. Høyer, P. Grandjean, T. Jørgensen, J. W. Brock and H. B. Hartvig, "Dieldrin as a Risk Factor for Breast Cancer and for Increased Mortality Once Breast Cancer Is Detected," Journal of Clinical Epidemiology, Vol. 2002, No. 53, 2000, pp. 323-330. http://www.ourstolenfuture.org/newscience/human/cancer /dieldrin.htm
doi:10.1016/S0895-4356(99)00165-1

[14] R. A. Cassidy, S. Natarajan and G. M. Vaughan, "The Link between the Insecticide Heptachlor Epoxide, Estradiol, and Breast Cancer," Breast Cancer Research and Treatment, Vol. 90, No. 1, 2005, pp. 55-64.

http://www.researchgate.net/publication/7963366_The li nk_between_the_insecticide_heptachlor_epoxide_estradi ol and breast cancer doi:10.1007/s10549-004-2755-0

[15] R. Cassidy, "Cancer and Chlordane-Treated Homes: A Pinch of Prevention Is Worth a Pound of Cure," Leukemia \& Lymphoma, Vol. 51, No. 7, 2010, pp. 1363-1364. http://www.toxfree.net/chlordane/Cassidy/cassidypdf/Can cerandChlordane-TreatedHomes.pdf doi:10.3109/10428194.2010.483304

[16] F. Falck Jr., A. Ricci Jr., M. S. Wolff, J. Godbold and P. Deckers, "Pesticides and Polychlorinated Biphenyl Residues in Human Breast Lipids and Their Relation to Breast Cancer," Archives of Environmental Health, Vol. 47, No. 2, 1992, pp. 143-146. http://www.ncbi.nlm.nih.gov/pubmed/1567239

[17] Z.-H. Li, X.-Y. Liu, N. Wang, J.-S. Chen, Y.-H. Chen, et al., "Effects of Decabrominated Diphenyl Ether (PBDE209) in Regulation of Growth and Apoptosis of Breast, Ovarian, and Cervical Cancer Cells," Environmental Health Perspectives, Vol. 120, No. 4, 2012, pp. 541-546. http://ehp03.niehs.nih.gov/article/info\%3Adoi\%2F10.128 9\%2Fehp.1104051 doi:10.1289/ehp.1104051

[18] S. Liu, S. Li and Y. Du, "Polychlorinated Biphenyls (PCBs) Enhance Metastatic Properties of Breast Cancer Cells by Activating Rho-Associated Kinase (ROCK)," PLoS One, Vol. 5, No. 6, 2010, p. e11272.

http://www.plosone.org/article/info\%3Adoi\%2F10.1371 \%2Fjournal.pone.0011272 doi:10.1371/journal.pone.0011272

[19] J. Muscat, J. Britton, M. Djordjevic, M. Citron, M. Kemeny, E. Devereaux, B. Pittman, S. Stellman, "Adipose Concentrations of Organochlorine Compounds and Breast Cancer Recurrence in Long Island, New York," Cancer Epidemiol Biomarkers and Prevention, Vol. 12, 2003, p. 1474. http://cebp.aacrjournals.org/content/12/12/1474.short

[20] A. P. Hoyer, T. Jørgensen, F. Rank and P. Grandjea, "Organo-Chlorine Exposures Influence on Breast Cancer Risk and Survival According to Estrogen Receptor Status: A Danish Cohort-Nested Case-Control Study," Biomed Central Cancer, Vol. 1, 2001, p. 8.

http://www.biomedcentral.com/1471-2407/1/8

[21] Z.-H. Li, X.-Y. Liu, N. Wang, J.-S. Chen, Y.-H. Chen, J.-T. Huang, C.-H. Su, F. K. Xie, B. Yu and D.-J. Chen, "Effects of Decabrominated Diphenyl Ether (PBDE-209) in Regulation of Growth and Apoptosis of Breast, Ovarian, and Cervical Cancer Cells," Environmental Health Perspectives, Vol. 120, 2012, p. 4.

http://ehp03.niehs.nih.gov/article/info\%3Adoi\%2F10.128 9\%2Fehp.1104051

[22] P. K. Mills and R. Yang, "Breast Cancer Risk in Hispanic Agricultural Workers in California," International Jour- 
nal of Occupational and Environmental Health, Vol. 11, No. 2, 2005, pp. 123-131.

http://www.ncbi.nlm.nih.gov/pubmed/15875887

[23] E. Lawrence, D. Hill, J. Hoppin, J. Lubin, C. Lynch, J. Pierce, C. Samanic, D. Sandler, A. Blair and M. Alavanja, "Pesticide Use and Breast Cancer Risk among Farmers' Wives in the Agricultural Health Study," American Journal of Epidemiology, Vol. 161, No. 2, 2005, pp.
121-135. doi:10.1093/aje/kwi022

[24] S. Hilaire, R. Mandal, A. Commendador, S. Mannel and D. Derryberry, "Estrogen Receptor Positive Breast Cancers and Their Association with Environmental Factors," International Journal of Health Geographics, Vol. 11, No. 1, 2011, p. 32.

http://www.ij-healthgeographics.com/content/10/1/32 doi:10.1186/1476-072X-10-32 